\title{
Market Expectations in the UK Before and After the ERM Crisis
}

\author{
Paul Söderlind* \\ Department of Economics \\ Stockholm School of Economics \\ 21 March 1999 (first version in December 1997)
}

\begin{abstract}
The British pound left the ERM on 16 September 1992 after a period of turbulence. UK monetary policy soon shifted to lower short interest rates and an inflation target was announced. This paper uses daily option prices to estimate how the market's probability distribution of the future marks/pound exchange rate and UK and German interest rates changed over the summer and autumn of 1992. The results show, among other things, how various policy decisions affected the market's assessment of the probabilities of realignments and lending rate cuts.
\end{abstract}

Keywords: Interest rates, exchange rates, futures, options, risk neutral distribution.

JEL: E43, E52, G13.

* Stockholm School of Economics and CEPR. Address: Stockholm School of Economics, PO Box 6501, SE-113 83 Stockholm, Sweden. E-mail: Paul.Soderlind@hhs.se. Telephone: +468-736-9601. I thank Bhupinder Bahra, Neil Cooper, Magnus Dahlquist, Alan Malz, Lars E.O. Svensson, and an anonymous referee for comments; Citibank, Neil Cooper, Martin Edlund, Antti Koivisto, Alan Malz, and Peter Macmillan for generous help with data. 


\section{Introduction}

This paper uses data on forward contracts and options to study the market expectations about UK interest rates and exchange rate around the ERM crisis 1992. The results show how the market's subjective probability distributions changed from day to day (from late June to late November1992) in response to policy measures and other events.

For the period before the pound left ERM on the 'Black Wednesday' (16 September 1992), we pay special attention to how the market responded to the government's attempt to stabilize the pound (for instance, the Ecu borrowing program on 3 September), and to the attempts of European policy coordination (for instance, the German interest rate cut 14 September). For the period thereafter, we focus on how the market perceived the piecemeal and tentative presentation of the new framework for monetary policy (for instance, the announcement of the inflation target on 8 October) and the expansionary monetary policy (for instance, the whole series of interest rate cuts).

The intuition for why option prices contain information about the market's subjective probability distribution is that an option is a bet. For instance, a call option has a positive payoff only if the price of the asset happens to exceed a given strike price. The option price should therefore reflect the perceived probability of this event. By combining the information from several options with different strike prices, we may be able to recover most of the market's subjective probability distribution.

This type of technique for extracting market expectations from financial prices have recently been applied to ERM crisis. For instance, (Malz 1996) and (Mizrach 1996) estimate 'risk neutral' distributions of the pound exchange rate for the period up to the end of September 1992, and (Campa and Chang 1996) calculates a minimum realignment intensity for the exchange rate using arbitrage arguments 
only.

This paper differs on several accounts. First, it studies a broader range of asset prices: the three month sterling and mark interest rates, a ten year sterling yield to maturity, and also the pounds/mark exchange rate. Second, it pays attention to both the ERM crisis in August and September 1992 and the announcement of the new UK monetary policy framework in October and November 1992. Third, it applies and extends the methods in (Söderlind and Svensson 1997), which are flexible enough to capture the huge swings in market expectations over the summer and autumn of 1992, but still theoretical enough to rule out negative probabilities and to allow a meaningful discussion of risk premia.

\section{Recovering Risk Neutral Distributions from Op- tion and Futures Prices}

A European call option gives the holder the right, but not the obligation, to buy an asset for the strike price, $X$, at the expiry date, $\tau$. The price of the asset is then $Q(\tau)$, so the option's payoff is the maximum of zero and $Q(\tau)-X$. In a frictionless market, the law of one price (assets with the same payoff structure have the same price) implies that the call option price, $C$, at the trade date $t$ is

$$
C(t, \tau ; X)=\mathrm{E}_{t}\{D(t, \tau) \max [0, Q(\tau)-X]\}
$$

where $D(t, \tau)$ is a nominal discount factor 1

(Söderlind and Svensson 1997) assume that the distribution of the logs of $D(t, \tau)$ and $Q(\tau)$, conditional on the information in $t$, is a mixture of $n$ bivariate normal distributions. ${ }^{2}$ Let $\phi(x ; \mu, \Omega)$ denote a normal multivariate density func-

\footnotetext{
${ }^{1}$ See, for instance, (Duffie 1992).

2 (Ritchey 1990), (Melick and Thomas 1997), and (Bahra 1996) assume that the risk-neutral distribution is a mixture of univariate log-normals. This is implied by the assumption of bivariate
} 
tion over $x$ with mean vector $\mu$ and covariance matrix $\Omega$. The weight of the $j^{t h}$ normal distribution is $\alpha^{(j)}$, so the probability density function, pdf, of $\ln D(t, \tau)$ and $\ln Q(\tau)$ is assumed to be

$\operatorname{pdf}\left(\left[\begin{array}{l}\ln D(t, \tau) \\ \ln Q(\tau)\end{array}\right]\right)=\sum_{j=1}^{n} \alpha^{(j)} \phi\left(\left[\begin{array}{l}\ln D(t, \tau) \\ \ln Q(\tau)\end{array}\right] ;\left[\begin{array}{l}\bar{d}^{(j)} \\ \bar{q}^{(j)}\end{array}\right],\left[\begin{array}{cc}\sigma_{d d}^{(j)} & \sigma_{d q}^{(j)} \\ \sigma_{d q}^{(j)} & \sigma_{q q}^{(j)}\end{array}\right]\right)$,

with $\sum_{j=1}^{n} \alpha^{(j)}=1$ and $\alpha^{(j)} \geq 0$. One interpretation of mixing normal distributions is that they represent different macro economic 'states', where the weight is interpreted as the probability of state $j$.

Let $i(t, \tau)$ be the spot interest rate on a bill with maturity date $\tau$, and $\Phi($.$) be$ the standardized normal distribution function. If $\bar{d}^{(j)}=\bar{d}$ and $\sigma_{d d}^{(j)}=\sigma_{d d}$ in 2), then the European call option price (1) has a closed form solution in terms of the spot interest rate, strike price, and the parameters of the bivariate distribution ${ }^{3}$

$$
\begin{aligned}
C(X) & =e^{-i(t, \tau)(\tau-t)} \sum_{j=1}^{n} \alpha^{(j)}\left[\exp \left(\bar{q}^{(j)}+\frac{1}{2} \sigma_{q q}^{(j)}+\sigma_{d q}^{(j)}\right) \Phi\left(\frac{\bar{q}^{(j)}+\sigma_{q q}^{(j)}+\sigma_{d q}^{(j)}-\ln X}{\sqrt{\sigma_{q q}^{(j)}}}\right)\right. \\
& \left.-X \Phi\left(\frac{\bar{q}^{(j)}+\sigma_{d q}^{(j)}-\ln X}{\sqrt{\sigma_{q q}^{(j)}}}\right)\right]
\end{aligned}
$$

A forward contract written in $t$ stipulates that, in period $\tau$, the holder of the contract gets one asset and pays $F(t, \tau)$. This can be thought of as an option with a zero strike price and no discounting. The forward price then follows directly from (3) as

$$
F(t, \tau)=\sum_{j=1}^{n} \alpha^{(j)} \exp \left(\bar{q}^{(j)}+\sigma_{d q}^{(j)}+\frac{\sigma_{q q}^{(j)}}{2}\right) .
$$

log-normals in (Söderlind and Svensson 1997). Mixtures of normals have recently been increasingly used in econometric studies (see, for instance, (Hamilton 1989)).

Without these restrictions, $\alpha^{(j)}$ in $\sqrt{3}$ is replaced by $\tilde{\alpha}^{(j)}=\alpha^{(j)} \exp \left(\bar{d}^{(j)}+\right.$ $\left.\sigma_{d d}^{(j)} / 2\right) / \sum_{j=1}^{n} \alpha^{(j)} \exp \left(\bar{d}^{(j)}+\sigma_{d d}^{(j)} / 2\right)$. In this case, $\tilde{\alpha}^{(j)}$, not $\alpha^{(j)}$, will be estimated from option data. Note that $\exp \left(\bar{d}^{(j)}+\sigma_{d d}^{(j)} / 2\right)$ is the $\tau-t$ period bill price, $\exp [-i(t, \tau)(\tau-t)]$, conditional on state $j$ and that $\sum_{j=1}^{n} \alpha^{(j)} \exp \left(\bar{d}^{(j)}+\sigma_{d d}^{(j)} / 2\right)$ is the actual bill price. 
There are several reasons for assuming a mixture of normal distributions. First, non-parametric methods often generate strange results, so we need to assume some parametric distribution. Second, it gives closed form solutions for the option and forward prices, which is very useful in the estimation of the parameters. Third, it gives the Black-Scholes model as a special case when $n=1$. Fourth and finally, it provides a useful framework for discussing the effect of risk premia (we will return to that issue later on).

We want to estimate the marginal distribution of the future asset price, $Q(\tau)$. From (2), it is a mixture of univariate normal distributions with weights $\alpha^{(j)}$, means $\bar{q}^{(j)}$, and variances $\sigma_{q q}^{(j)}$. The basic approach in this paper is to try to 'back out' these parameters from data on option and forward prices by exploiting the pricing relations (3)-(4). To do that we need data on at least at many different strike prices as there are parameters to estimate.

One problem with this approach is that the means backed out from option and forward price data will be $\bar{q}^{(j)}+\sigma_{d q}^{(j)}$ rather than the correct $\bar{q}^{(j)}$. This is apparent from 3 - 4 : whenever there is a $\bar{q}^{(j)}$, there is also a $\sigma_{d q}^{(j)}$. These covariance terms reflect risk premia, which have relatively little information about. The main approach in the literature is therefore is to ignore this problem by assuming that risk premia are zero (here $\sigma_{d q}^{(j)}=0$ ). This also what I do for most of this paper. To be clear about this assumption, the estimated distributions are denoted 'risk neutral distributions' 4 We will later return to a more detailed discussion of how the estimated distributions can be adjusted if the risk premia are non-zero.

\footnotetext{
${ }^{4}$ See (Cox and Ross 1976) for risk neutral valuation of contingent claims.
} 
a. Trade intensity

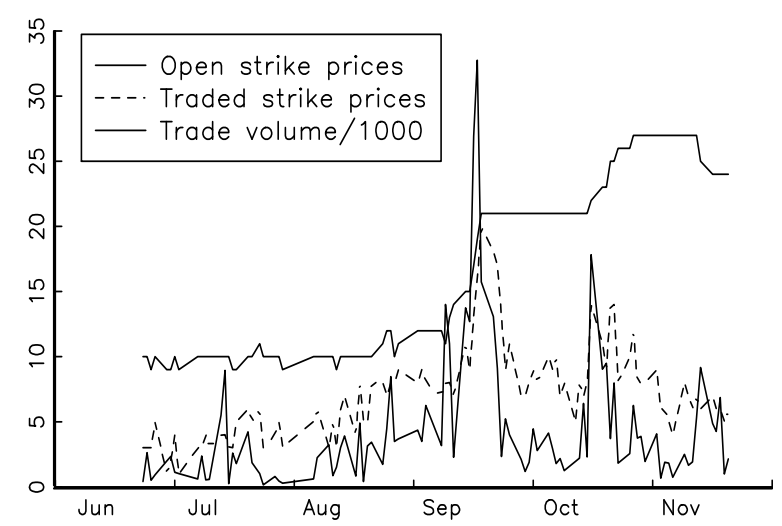

c. Traded strike prices

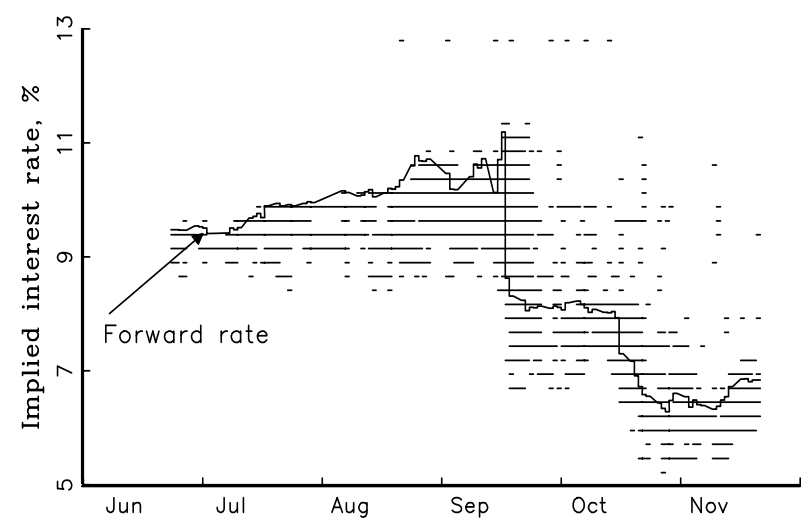

b. Open strike prices

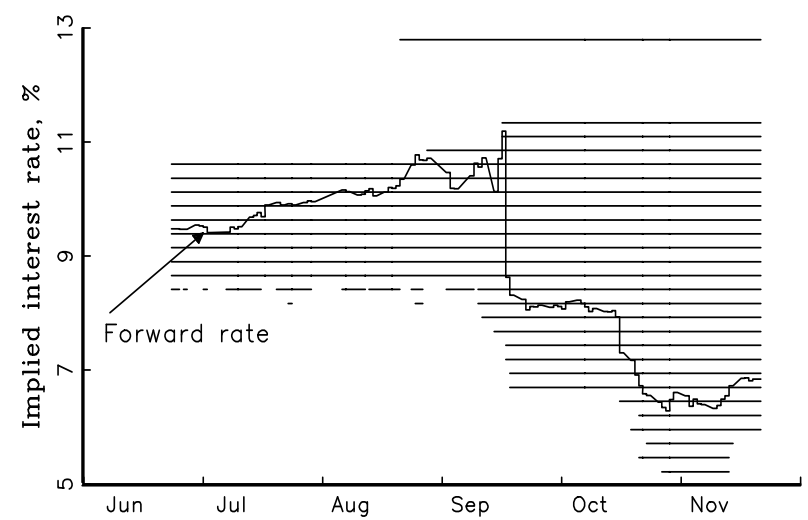

Figure 1: Trade statistics for the short sterling interest rate option

\section{Data}

The main data are daily option quotes for four assets: three month sterling interest rate (denoted short sterling below) futures, three month mark interest rate (denoted Euromark) futures, long UK government bond (denoted long gilt) futures, and the marks/pound exchange rate. The sample includes every trade day between 23 June 1992 and 20 November 1992.

The interest rate and bond options are from London International Futures and 
Options Exchange (LIFFE) and are paid at exercise, not at purchase. The daily settlement prices, fixed by an administrative decision at the close of business, are used for the 'marking to market'. This ensures that investors each day receive their gains and pay their losses due to price changes. These institutional features ('futures style margining') have three important consequences. First, the interest rate term in (3) drops out. Second, there is essentially no opportunity cost of holding the option, so the LIFFE options, which are American (can be exercised before or on expiry date), are actually priced as European options (can only be exercised on expiry date) $5^{5}$ This is of great help since it is hard to arrive at closed form expressions for prices of American options. Third, the settlement prices of options with open positions affect the daily cash flow of at least two investors (issuer and holder). This should provide incentives to the members of the exchange (some of which hold positions, others act as brokers) to 'battle out' settlement prices close to the equilibrium prices.

For the Euromark and short sterling I use prices on the interest rate futures with delivery 15 and 17 December 1992, respectively, and settlement prices on options on the futures, with expiry on 14 and 16 December 1992, respectively. The futures prices are assumed to be close approximations of the forward prices. The futures price and the strike prices are quoted as 100 minus the three month simple annual interest rate in percent, where the day count is actual $/ N$ (the price of the bill with the simple interest rate $y$ is therefore $1 /(1+$ days $/ N * y / 100))$. The continuously compounded interest, $i$, rate solves the equation that the price of the bill equals $\exp (-i \times$ days $/ N)$. For the Euromark $N=360$ and for the short sterling $N=365$. More details are found in (LIFFE 1997b) and (Blake 1990).

Figure 1 a illustrates the trade intensity of the short sterling option by showing the number of different strike prices with open positions and trade on each day.

\footnotetext{
${ }^{5}$ See (Chen and Scott 1993) for a theoretical argument.
} 
It also shows the number of contracts (à 500,000 pounds) traded. According to all three series, the trade intensity was fairly high after mid August, with marked peaks in mid September and mid October. The average number of options with open positions and trade were 17 and 7 , respectively, and the average number of traded contracts was 4365 .

Figure 1$] b$ shows which short sterling options that had open positions on each day; Figure $1, c$ does the same for trade. The strike prices (vertical axis) have been transformed into interest rates in order to facilitate the comparison with the estimation results presented later. The thick solid curve is the forward interest rate. Until late August, most trade was in options with strike (interest) rates at or below the forward rate, so the data contains relatively little information about the shape of the distribution above the forward rate. However, there were sizeable open positions (several thousand contracts) for strike rates above the forward rate, and the prices on those options should contain useful information (see the previous discussion). In most of the paper, I will therefore use all options with open positions (I will later compare with the results obtained from using only traded options). After mid September there were generally open positions and trade for a wide range around the forward rate.

The trade intensity of the Euromark option was similar to that of the short sterling option with an average number of 13 and 6 options with open positions and trade, respectively, and an average of 3669 traded contracts (à 1,000,000 marks).

The LIFFE interest rate options are not options on a bill/bond, but on futures on a bill/bond. This distinction does not matter if three conditions are satisfied: (i) the option is European; (ii) the option and the futures have the same maturity; and (iii) only one unique bond/bill can be delivered into the futures contract. The options on the short sterling and Euromark satisfy all three conditions, but the option on the long gilt futures does not. 
For the long gilt I use prices on the bond futures with delivery on any day in December 1992, and settlement prices on options on the futures with expiry 23 November 1992. Delivery can be made of any bond on the 'List of Deliverable Gilts', and the invoice amount is the futures price times the price factor, plus accrued interest (details are found in (LIFFE 1997a) and (Blake 1990)).

Only two different bonds were actually delivered in significant amounts into the futures during the period September 1991 to March 1993, in spite of changing yield curves which could alter the 'cheapest to deliver bond'. Moreover, most futures positions were closed within two weeks of the expiry date of the option. It therefore seems reasonable to assume that both the option and futures expired on 1 December 1992, and that only these two specific bonds would be delivered. This assumption does not influence the estimation, but it allows me to present the results in terms of the yield to maturity, which may be more informative than the bond price. It turns out that the two bonds give very similar results, so only the $13.5 \%$ coupon bond maturing in 2004 is showed in the subsequent figures. If the bond pays the coupon $c$ at the future dates $s_{1}, \ldots, s_{K}$ (assuming today is time zero) and a principal of one at $s_{K}$, then the continuously compounded yield to maturity, $y$, solves the equation that the invoice amount equals $c \Sigma_{k=1}^{K} \exp \left(-y s_{k}\right)+$ $\exp \left(-y s_{K}\right)$

The evolution of the trade intensity of the long bond option was similar to that of the short sterling option, even if the long bond option was, on average, less traded. The average number of strike prices with open positions and trade were 11 and 5, respectively, and the average number of traded contracts (à 50,000 pounds) was 2430 .

The marks/pound exchange rate options are over-the-counter European options on the exchange rate one month from the trade date. This is used since no European cross rate options were traded on public exchanges before the ERM 
crisis. The quotes, recorded by Citibank at noon London time, are for three different combinations of call and put options (at-the-money forward, 25-delta 'risk reversals' and 'strangles'). They allow us to calculate call option prices at three different strike prices: below, at, and above the current forward rate, respectively, with the exact location depending on the uncertainty of the market. With so few options, we will probably only recover the broad outline of the risk neutral distribution. These data are described in more detail by (Malz 1996), who notes that liquidity was generally good, with the notable exceptions of 15 and 16 September.

In addition to the option and futures data described above, I also use interest and exchange rate data from Bank of International Settlements (one, three, and six month sterling euro deposits, one month mark euro deposits, and the marks/pound exchange rate).

\section{Results}

\subsection{Estimation}

In estimating the distributions of the short sterling interest rate, long gilt yield to maturity, and the marks/pound exchange rate I use a mixture of two normal distributions. For each trade day, the parameters are estimated by minimizing the sum of squared price errors of options and futures. The probabilities of the two states are restricted to be the same for all three assets. In practice, this does not make much difference for the interest rate distributions, but it is necessary for estimating the exchange rate distribution since we have only three exchange rate options. The distribution of the Euromark interest rate is also a mixture of two normal distributions, but is estimated separately since there is no strong reason to believe that Germany had the same macro economic 'states' as the UK.

As an example, consider Figure 2, which shows some estimation results for 
the short sterling on 16 September. Figure 2 a plots the option prices against the $\log$ strike prices. It shows that the model fits the prices of the 17 available options fairly well, even if the prices of options with very high strike prices are overestimated. This is perhaps more easily seen in Figure 2.c, which shows the 'implied volatilities', which are obtained by backing out the only unknown parameter in the Black-Scholes formula from in each option separately. If the assumption of only one normal distribution was correct, then the implied volatilities should be on a horizontal line. For this trade day they are clearly not. In contrast, the estimated model seems to capture most of the features of data (fitted values are marked by the solid curve). I will later do a formal test of one versus two normal distributions. The estimated probability density function in Figure 2 b (thick solid curve) is clearly skewed, which is fitted by mixing two normal distributions (thin solid and dashed curves).

\subsection{The Background}

The background to the events during the summer and autumn 1992 was that the tight German monetary policy after the re-unification resulted in high interest rates and appreciation of the ERM currencies against the US dollar. The adverse effects on several of the ERM countries eventually undermined the credibility of the prevailing exchange rate parities. The British pound was vulnerable since the slow growth and low inflation in the UK created strong demands for lower interest rates, at the same time as a large number the government's own supporters questioned the fixed exchange rate regime and the upcoming ratification of the Maastricht treaty.

The UK monetary authorities eventually proved unwilling to accept very high interest rates in order to defend the exchange rate. The pound was suspended from the ERM on 16 September 1992. Monetary policy soon shifted to significantly 
lower short interest rates. Somewhat later, a fairly ambitious inflation target was announced, and the Bank of England was granted a more independent status.

\subsection{Inside the ERM}

Figures 3 a- $d$ illustrates the estimation results for each of the four assets by showing the expected values (forward rates) and the 5th and 95th percentiles of the estimated risk neutral distributions. The latter will henceforth be called the 'market's $90 \%$ confidence interval'. In general, we would expect the width of the market's confidence interval to decrease if the trade date gets closer to the expiry date of the option, as it does for the interest rate and bond options, but not for the exchange rate option ${ }^{6}$ All interest rates are continuously compounded interest rates (see Section 3).

The period from early July to mid August was characterized by a slowly depreciating expected exchange rate and increasing expected sterling interest rates. The figures show that uncertainty - the width of the market's confidence intervals - increased steadily over this period. The market's $90 \%$ confidence interval for the exchange rate crossed the lower ERM band limit (2.778 marks/pound) for the first time in mid July, even if the exact numbers are uncertain since the estimates are based on only three exchange rate options and a forward rate.

In late August, the US dollar depreciated rapidly and a series of concerted central bank interventions failed to strengthen the dollar. 77 This seems to have

\footnotetext{
${ }^{6}$ In the Black-Scholes model, the standard deviation, and therefore the width of the confidence interval, decreases with the square root of the time to expiry.

7 The following is a lists of commonly cited events. July 16: Italian and German discount rates raised. July 30: rumours about French polls in favour of 'no'. August 11, 21, and 24: fall of dollar in spite of concerted inventions. September 3: UK government announces Ecu 10 billion borrowing programme to support the pound. September 5: meeting of EU finance ministers and central bankers. September 8: FIM abandons Ecu peg. September 13: ITL devalued. September 14: reduction in German discount rate. September 16: the pound is suspended from ERM. September 20: small majority in favour of EMU in French referendum. October 8: UK chancellor announces inflation target. October 16: Bank of England cuts the lending rate. October 29: Mansion House speech by UK chancellor. November 12: Autumn Statement in Parliament by UK chancellor. Announcement of lending rate cut the next day. See, for instance, (Bank of
} 
increased tensions within the ERM (the effect on the ERM currencies was asymmetric). A few days later, French opinion polls predicted, for the first time, a small majority against EMU in the upcoming referendum (to be held on 20 September). Over a couple of days, the expected short sterling and long gilt increased by $0.5 \%$, the expected pound exchange rate depreciated $1 \%$, and the uncertainty grew significantly. In contrast, the distribution of the Euromark was almost unaffected.

The widening of the market's confidence intervals was mostly due to the emergence of elongated upper tails of the interest rate distributions and an elongated lower tail of the exchange rate distribution. The market clearly believed that UK monetary policy was in big trouble. For instance, the risk neutral probability of a short sterling above $10.7 \%$ increased from $26 \%$ on August 20 to $46 \%$ on 26 August. Similarly, the risk neutral probability of an exchange rate below the band limit (2.778) increased from around $15 \%$ on 20 August to around $40 \%$ on $26 \mathrm{Au}-$ gust. $]^{8}$

This pattern of market expectations of a cheaper pound and higher sterling interest rates was to repeat itself on several occasions before the pound finally left the ERM on 16 September. Afterwards, we know that the direct result of leaving the ERM was a cheaper pound, and lower interest rates, so the market got it only half right. So what kind of scenario did the market consider? Probably a small realignment - too small to ease the pressure on the pound, so the interest rate differential towards the mark would have to remain high. The market did certainly not expect the pound to fall as it did - to 2.642 on 17 September: this was clearly below the market's $90 \%$ confidence interval.

The crisis in late August appears to have been brought to an end by the an-

England 1992) and (Stephens 1996) dicussions of these events.

8 This is similar to the findings by (Malz 1996), who estimates realignment probabilities of up to $40 \%$ in late August. (Mizrach 1996) estimates the risk neutral probability that the pound should depreciate more than 3\% against the US dollar (using a different method). He finds that this probability increases from early September, but reaches a significant level only on 15 September. 
nouncement of the Ecu borrowing program to support the pound (on 3 September). The expected UK interest rates and exchange rate, as well as the uncertainty, then returned to their mid August values.

The respite was short, and a second crisis developed a couple of days later, possibly prompted by the further easing of US monetary policy, and worsened by the failed meeting of the European finance ministers and central bankers over the weekend 5 and 6 September. The expected exchange rate depreciated rapidly the following Monday. The European exchange rate market was now very turbulent, and on 8 September the Finnish markka abandoned the unilateral Ecu peg. On the same day, the expected short sterling rose to the same levels as in late August, and the uncertainty about both the exchange rate and the short sterling increased. One difference to the crisis in late August, however, was that the expected long gilt remained unchanged this time.

This second crisis was temporarily checked around the next weekend (1213 September): the Italian lira was realigned on 13 September, and the German discount and Lombard rates cut the next day. This generated the first significant change in the expected Euromark since the start of the sample - it decreased by $0.6 \%$ to $8.8 \%$, but the uncertainty remained small. This change was within the market's $90 \%$ confidence interval, but a larger change would not have been. For instance, a December Euromark of 8.3\% (the expected value on 16 September) had only a $5 \%$ probability on 11 September. This gives some perspective on the common claim that 'the reductions of 50 basis points in the German discount rate ...were smaller than had been hoped for' ((Bank of England 1992), page 392, emphasis added). Maybe, but not smaller than expected.

In any case, the expected short sterling returned to its mid August value, and the expected exchange rate appreciated somewhat. This is similar to what happened after the Ecu borrowing program (3 September). However, there is one 
important difference: the uncertainty did not fall back this time.

\subsection{Out of the ERM}

On 16 September, the 'Black Wednesday', the ERM was in a state of chaos: several currencies were forced below the band limits and central banks intervened heavily. At the close of business (London), the expected Euromark had fallen by $0.5 \%$ to $8.3 \%$. The shape of the Euromark distribution had also changed significantly - for the first time since the start of the sample. It was now much wider than before and had an elongated lower tail; the market did not rule out further cuts in the mark interest rate. The expected short sterling, in contrast, had increased to roughly the same levels as in late August, and the uncertainty was extremely large. The uncertainty about the long gilt had also increased somewhat, but the expected value was actually somewhat lower than the day before.

Trade in all three interest rate options was brisk on 16 September. In contrast, there was little trade in the over-the-counter exchange rate option (see (Malz 1996)), so we should probably treat the results for it with extra caution. In any case, the expected exchange rate was (by noon London time) essentially the same as the day before, but the width of the market's confidence interval almost twice as large - mostly because of an elongated lower tail.

The pound was suspended from the ERM after 7.30 pm (GMT). The next day, the expected exchange rate depreciated more than 5\% against the mark, but the exchange rate distribution still had an elongated lower tail; the market was very uncertain about where the floating pound would go, and did not rule out further depreciation. On the same day, the expected short sterling fell more than $2 \%$. The elongated upper tail of its distribution was cut off, but the uncertainty remained large.

These dramatic changes were big surprises for the market. On 14 September, 
the probability of a short sterling below $8.6 \%$ (the expected value as of 17 September) was just $10 \%$. Similarly, the probability of an exchange rate below 2.64 (the expected value as of 17 September) also appears to be very small.

To illustrate how these dramatic changes map into changes in option prices, Figure 4 $a$ shows the short sterling option prices against the strike (interest) rates on 14, 16, and 18 September 1992, and Figure $4 b$ shows the risk neutral distributions for the same days. The estimated distribution shifted to higher interest rates between 14 and 16 September, which meant a lower probability of a positive option payoff (actual interest rate below the strike rate). The options were therefore less valuable. Exactly the opposite holds for the change between 16 and 18 September. 9

The distribution of the Euromark and the long gilt did not change much on 17 September. The latter might appear surprising, but it seems as if the $13.5 \%$ coupon bond maturing in 2004 (with a duration of approximately six years) was located at a point where the effects of lower expected short interest rates and higher expected very long rates cancelled each other. This is illustrated in Figure 5, which shows estimated UK yield curves on 14 and 18 September. ${ }^{10}$

\footnotetext{
${ }^{9}$ One could possibly suspect that the lonely option with a strike rate of approximately $13 \%$ is very important for the results. That would be problematic, since this option was traded infrequently (see Figure 1). Fortunately, this is not the case. For instance, on 16 September, estimation based on only traded options (excluding the $13 \%$ option) gives essentially the same distribution as in Figure $4 \mathrm{~b}$ (based on all options with open positions). The reason is that the $13 \%$ strike rate is so high that this option was almost certain to be exercised, and therefore contained essentially the same information as the forward rate. This is particularly clear on 18 September when an investor could either enter a foward contract which forced him to pay 91.6 in December 1992 to get a three month bill, or an option contract which forced him to pay 4.6 in December 1992 in return for the right to aquire the same bill for the strike price 87 . Since $87+4.6=91.6$, the market did not value the right to not exercise the option (if the bond price would be below 87, that is, the interest rate above $13 \%$ ).

${ }^{10}$ Estimated extended Nelson and Siegel yield curve model (see (Svensson 1995) or (Söderlind and Svensson 1997)). Estimation by Sveriges Riksbank.
} 


\subsection{Outside the ERM}

The first two weeks outside the ERM brought an ongoing depreciation of the expected exchange rate, but fairly stable expected interest rates. There are no clear signs of any effects of the French voters' approval of the Maastricht treaty on 20 September, and the UK lending rate cut on 22 September (from 10\% to 9\%) seems to have been anticipated.

The uncertainty remained very large throughout September, probably because it was unclear what kind of monetary policy framework the UK government would put in place of the fixed exchange rate. Expectations about policy announcements around the Conservative Party conference possibly played a role in the turbulence in early October: the expected long gilt increased rapidly, the expected exchange rate depreciated, and the uncertainty grew. The expected short sterling was not affected, but the uncertainty around it increased. The pound recovered already the next day (6 October), but the problems were not over. The exchange rate uncertainty stayed large, and the expected long gilt increased even further. Calm was restored only on 8 October, perhaps because of the announcement of a UK inflation target that day.

The expected short sterling dropped $0.6 \%$ (to $7.3 \%$ ) on 16 October as the Bank of England cut the lending rate (from $9 \%$ to $8 \%$ ). This took the market by some surprise; two days earlier, the risk neutral probability of a December short sterling less than $7.3 \%$ was only $13 \%$. Both the expected short sterling and the expected long gilt continued to decrease for several weeks. This was possibly driven by the Prime Minister's new 'strategy for growth' announced on 20 October, which aimed at 'early and strong recovery' (see (Stephens 1996)). There were signs of market expectations about even further interest rate cuts: the lower tail of the short sterling distribution was elongated.

The chancellor delivered his Autumn statement in Parliament on 12 November 
and announced a lending rate cut (from $8 \%$ to $7 \%$ ) to take place the next day. The market responded by increases in the expected short sterling and long gilt, but the uncertainty decreased dramatically. It seems as if the speech surprised the market by signalling, credibly, it seems, that no further cuts should be expected.

\section{Robustness Check}

This section discusses the estimation errors, the effect of using only traded options, and risk premia. To economize on space, the attention is mostly focused on the short sterling, which is at the center of the main results presented before.

\subsection{Precision of the Estimators}

The mixture of two normal distributions with 5 parameters seems to be able to capture most of what is going on in the, on average, 18 different short sterling options/forward rates. The average price error is very close to zero for most days. The variance of the price errors is less than $0.5 \%$ of the variance of the option prices (that is, $R^{2}>0.995$ ) for every day in the sample. If we instead look at all daily observations of a particular option (strike price), then the variance of the price errors is also a very small fraction of the variance of the option prices. For options with strike interest rates above $6 \%$, this fraction is always less than $0.25 \%$, and it is between $1 \%$ and $9 \%$ for options with strike rates between $5.2 \%$ and $5.75 \%$. However, these latter options had open positions only during a few weeks in late October and early November (see Figure 1.b).

As a consequence of the small price errors, the uncertainty about the 5th and 95th percentiles of the estimated risk neutral distributions in, for instance, Figure 3. a, should be small. To verify that, I reestimate the model on 100 simulated data sets for the whole sample, where the option and forward prices are the values 
implied by the original parameter estimates (from data) plus error terms. I try two different ways of generating the error terms: pseudo-random numbers from an iid normal distribution with the same variance as the original price errors, and resampling of the price errors themselves ('bootstrapping'). In either case, the simulated $90 \%$ confidence interval for the 5th (95th) percentile of the risk neutral distribution is very narrow; it is less than 4 (8) basis points wide on most days, and 8 (26) on the worst day.

\subsection{Options with Open Positions versus Options with Trade}

The results presented thus far have been based data for all options with open positions. I argued earlier that the institutional features of the options exchange (LIFFE) make this a sensible approach. Still, it is interesting to see how estimation using only traded options would change the results, especially since there was relatively little trade in options with strike (interest) rates above the forward rate before mid September (see Figure 1.c).

Once again, the 5th and 95th percentiles of the estimated risk neutral distributions are changed fairly little. For instance, for the short sterling in Figure 6 a, the difference for the 5 th percentile is less than 2 basis points for most days, and 9 basis points on the worst day. Not surprisingly, the difference is somewhat larger for the 95th percentile - before mid September. The peaks in late August/early September are typically 15-30 basis points lower when only traded options are used. This is, however, only a small fraction of the movements in the 95th percentile over this period. 


\subsection{Risk Premia}

The results presented thus far are for the risk neutral distributions, which coincide with the 'true' distributions only if there are no risk premia, as discussed in Section 2. If there are risk premia, then we would ideally like to adjust the estimated risk neutral distribution by shifting the $j$ th normal distribution by $\sigma_{d q}^{(j)}$ to the left to recover the true distribution.

We cannot observe these covariances directly, but if we can find some measure of the risk premia then we can at least make a reasonable assessment of their importance for the distributions.

It is straightforward to show the expected value of the risk neutral distribution equals the forward price, $F(t, \tau)$, in (4). In contrast, the expected value of the true distribution, $\mathrm{E}_{t} \ln Q(\tau)$, equals $\sum_{j=1}^{n} \alpha^{(j)} \bar{q}^{(j)}$. The difference of the logs, $\ln F(t, \tau)-\mathrm{E}_{t} \ln Q(\tau)$, is the traditional risk premium. For the short sterling, it is proportional to the forward term premium, that is the difference between the forward and expected interest rate. If we knew this term premium and were willing to make assumptions about the ratios $\sigma_{d q}^{(j)} / \sigma_{d q}^{(1)}(j=2, . . n)$, then we can solve for the true distribution. Here, I assume that $\sigma_{d q}^{(2)} / \sigma_{d q}^{(1)}$ equals the ratio of the standard deviations of the two normal distributions, and I explore two different assumptions about the term premium.

In Figure 6 b the term premium is predicted from a regression of ex post term premia on the lagged forward rate and three month interest rate. For the daily sample 28 November 1979 to 31 August 1997 (excluding 1992), the average ex post term premium is virtually zero, and the regression coefficients are 0.59 and 0.55 , respectively ${ }^{11}$ The regression predicts very small term premia for the period before the pound left the ERM (when forward rate was close to the spot rate), but

11 These coefficients are very similar to what (MacDonald and Macmillan 1994) found on a monthly 1989:10-1992:10 sample of survey data of interest rate expectations, but somewhat larger (in magnitude) than (Gerlach and Smets 1995) found on monthly ex post data for 1968:4-1993:12. 
term premia of $-0.5 \%$ to $-1 \%$ for the period out of ERM (when the forward rate was lower than the spot rate). The market's 'true' confidence intervals are then $0.5 \%$ to $1 \%$ above the market's risk neutral intervals for the period after 16 September.

In Figure 6 c, the term premium is, entirely ad hoc, assumed to be proportional to the standard deviation of the risk neutral distribution, in such a way that the term premium is $1 \%$ on 16 September and essentially zero at the end of the sample. The main effect is to shift the distribution down between late August and mid October, but it changes few of the previous conclusions about how the distribution changed over time - except that the movements around 16 September are moderated. Interestingly, even if these term premia are ad hoc, they correspond fairly well to the survey evidence in (MacDonald and Macmillan 1994). Their figures imply that the forward term premium(three month interest rate, settlement data three months ahead, mean of survey answers) was $-0.1 \%$ in early July, $0.3 \%$ in early August, $0.5 \%$ in early September, and $0 \%$ in early October. The term premia used in Figure 6.c are $0 \%, 0.3 \%, 0.5 \%$, and $0.3 \%$ for the same dates. Of course, it could still be the case that the risk premia went wild around mid September.

\subsection{The Number of States}

We have shown that the mixture of two normal distributions is able to capture most of what is going on in data. We now argue that one normal distribution (the Black-Scholes model) is not enough. First, it restricts the distribution to be symmetric around the mean, which would hide interesting information in Figure 3 where the asymmetries played an important role. Second, it leads to larger and systematic price errors. For instance, in Figure 2 $\mathrm{c}$ it seems clear that only one normal distribution leads to systematic errors in the 'implied volatility'. A formal test of the hypothesis of one normal distribution against two normal distributions is tricky, however. The reason is that under the null hypothesis that the means 
and standard deviations are equal in the two distributions (so effectively $n=1$ ), the relative weight of the two distributions is unidentified (the loss function is flat in that dimension). This implies that test statistics (likelihood ratios) have nonstandard distributions.

Several different ways of attacking this problem have been suggested. Hansen (1992, 1996) calculates, more or less by numerical integration, an $x \%$ critical value of the likelihood ratio such that the probability of rejecting a true null hypothesis is at most $x \% .12$ Other authors like (McLachlan and Basford 1988) and (Cecchetti, Pok-Sang, and Nelson 1990), simulate data under the null hypothesis $(n=1)$ and reestimates the model for both $n=1$ and $n=2$ on each simulated sample. The $x \%$ critical values is then taken to be the $100-x$ percentile of the simulated likelihood ratios $\sqrt{13}$ Both these approaches are computationally demanding.

These methods deliver similar results. The null hypothesis of one normal distribution is easily rejected, at the $5 \%$ level, in favour of the alternative hypothesis of two distributions for most days (at least 99 of the 108 days). Exceptions are the early part of the sample.

\section{Summary}

This paper studies how market expectations about future UK monetary policy changed over the summer and autumn of 1992. The period before 'Black Wednesday' (16 September) was marked by a series of small crises when the UK interest rates increased and the pound depreciated towards the lower ERM band limit. Af-

\footnotetext{
12 This method requires 'concentrating out' the identified nuisance parameters (here the means and the standard deviations of the first normal distribution) from the likelihood function. This is here done for a grid of the mean and standard deviations of the second normal distribution, as well as for the relative weight. The grid has $10 \times 10 \times 10$ points.

13 The number of artificial samples is restricted to 100 . The shocks are generated in the same way as in section about precision of the estimators.
} 
ter the pound left the ERM, short UK interest rates were lowered in number of steps and a new framework for monetary policy (including inflation targets) was put in place of the fixed exchange rate.

This paper estimates a time series of risk neutral distributions from daily option prices on the pounds/mark exchange rate, a ten year sterling yield to maturity, the three month sterling interest rate, and the three month mark interest rate. The estimation is done for a sample of daily price quotes for the period between late June to late November 1992.

The estimated risk neutral distribution is a mixture of lognormal distributions. It is derived from a theoretical asset pricing framework where the conditional distribution of the asset price and the stochastic discount factor is a mixture of bivariate lognormal distributions. This theoretical framework gives a closed form solution for the option price and provides a useful basis for discussing the effects of risk premia. The estimation procedure picks parameters of the distribution in order to minimize the squared difference between predicted and actual option prices.

While forward rates measure the market's (risk neutral) mean of a future asset price, option data can give an estimate of the entire (risk neutral) distribution. This allows us to give quantitative answers to questions like the following. How uncertain was the market? What probability did the market assign to a realignment? Did the market attach a higher probability to an increase in the short interest rate than to a decrease?

Several interesting results emerge from the estimates. First, the path to the 'Black Wednesday' was marked by a series of small crises in late August and early September 1992. During each of these, the distributions of the future UK interest rates and marks/pound exchange rate widened because the market started to believe in the possibility of really high interest rates and a moderate realignment. 
(The actual outcome was a large devaluation and much lower interest rates.) Second, the announcement of the UK inflation target on 8 October, brought down the long UK interest rates as well as the uncertainty about them. Third, the Autumn Statement by the UK chancellor on 12 November, seems to have put an end to the uncertainty about the future monetary policy: the distribution of future UK interest rates narrowed dramatically immediately after the speech.

\section{References}

BAHRA, B. (1996): "Probability Distributions of Future Asset Prices Implied by Option Prices," Bank of England Quarterly Bulletin, 36, August 1996(3), 299311.

BANK OF ENGLAND (1992): Quarterly Bulletin, November.

BlaKe, D. (1990): Financial Market Analysis. McGraw-Hill, London.

CAmpa, J. M., And P. H. K. Chang (1996): “Arbitrage-Based Tests of TargetZone Credibility: Evidence from ERM Cross-Rate Options," American Economic Review, 86, 726-740.

Cecchetti, S. G., L. Pok-Sang, And M. C. Nelson (1990): “Mean Reversion in Equilibrium Asset Prices," American Economic Review, 80, 398-418.

Chen, R.-R., And L. ScotT (1993): "Pricing Interest Rate Futures Options with Futures-Style Margining," Journal of Futures Markets, 13, 15-22.

Cox, J. C., And S. A. Ross (1976): “The Valuation of Options for Alternative Stochastic Processes," Journal of Financial Economics, 3, 145-166.

Duffie, D. (1992): Dynamic Asset Pricing Theory. Princeton University Press, Princeton. 
Gerlach, S., And F. SMETS (1995): “The Term Structure of Euro-Rates: Some Evidence in Support of the Expectations Hypothesis," Working Paper No. 28, Bank of International Settlements.

Hamilton, J. D. (1989): “A New Approach to the Economic Analysis of Nonstationary Time Series and the Business Cycle," Econometrica, 57, 357-384.

Hansen, B. E. (1992): “The Likelihood Ratio Test under Nonstandard Conditions: Testing the Markov Switching Model of GNP," Journal of Applied Econometrics, 7, S61-S82.

(1996): "Erratum: The Likelihood Ratio Test under Nonstandard Conditions: Testing the Markov Switching Model of GNP," Journal of Applied Econometrics, 11, 195-198.

LIFFE (1997a): Government Bond Futures.

(1997b): Short Term Interest Rates: Futures and Options.

MacDonald, R., AND P. Macmillan (1994): “On the Expectations View of the Term Structure, Term Premia and Survey-Based Expectations," Economic Journal, 104, 1070-1086.

Malz, A. M. (1996): "Using Option Prices to Estimate Realignment Probabilities in the European Monetary System: The Case of Sterling-Mark," Journal of International Money and Finance, 15, 717-748.

MCLAChlan, G. J., And K. E. BASFORD (1988): Mixture Models: Inference and Applications to Clustering. Marcel Dekker Inc, New York.

Melick, W. R., And C. P. Thomas (1997): "Recovering an Asset's Implied PDF from Options Prices: An Application to Crude Oil During the Gulf Crisis," Journal of Financial and Quantitative Analysis, 32, 91-115. 
MizRACH, B. (1996): “Did Option Prices Predict the ERM Crises?, Working Paper 96-10, Rutgers University.

Ritchey, R. J. (1990): "Call Option Valuation for Discrete Normal Mixtures," Journal of Financial Research, 13, 285-296.

SöDERLind, P., ANd L. E. O. Svensson (1997): "New Techniques to Extract Market Expectations from Financial Instruments," Journal of Monetary Economics, 40, 383-429.

Stephens, P. (1996): Politics and the Pound: The Conservatives' Struggle with Sterling. Macmillan.

Svensson, L. E. O. (1995): "Estimating Forward Interest Rates with the Extended Nelson Siegel Method," Sveriges Riksbank Quarterly Review, (3), 1326. 
a. Option prices

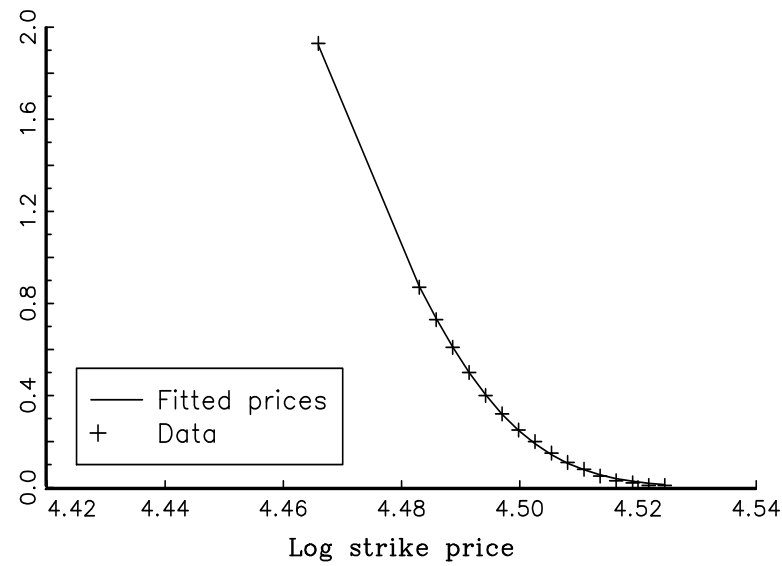

c. Implied volatility

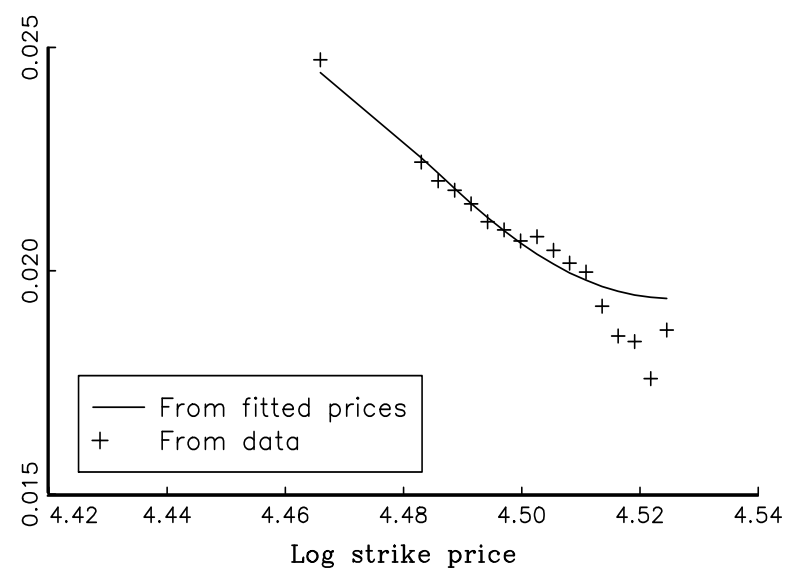

b. Probability density function

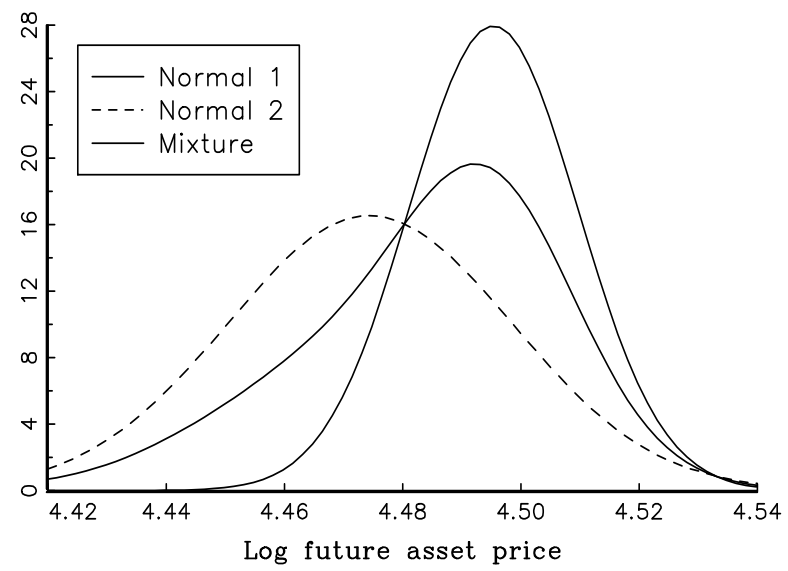

Figure 2: Data and results for short sterling interest rate option on 16 September 1992 
a. Short sterling

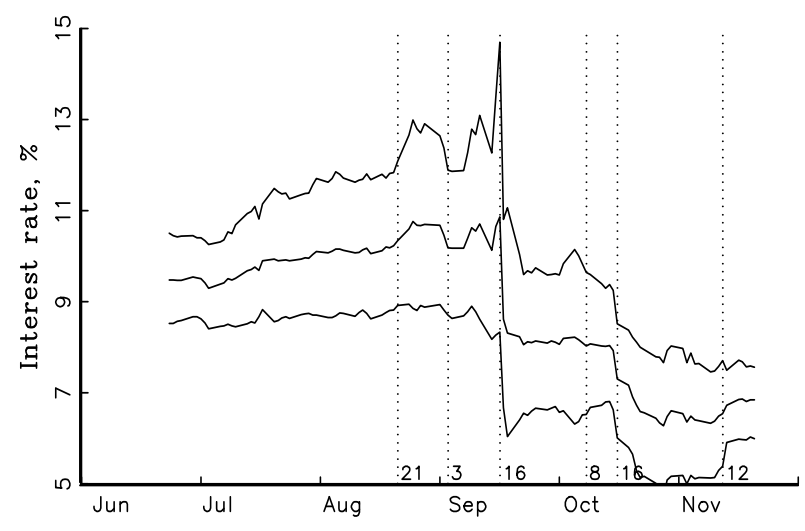

c. Exchange rate

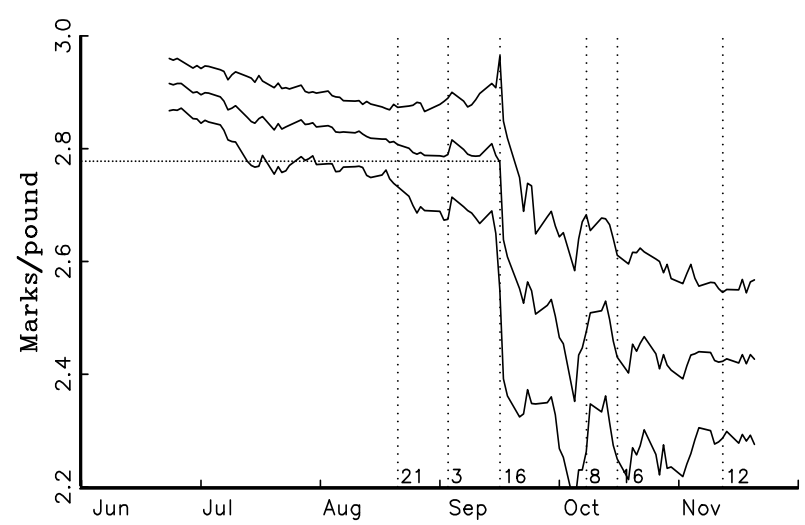

b. Long gilt

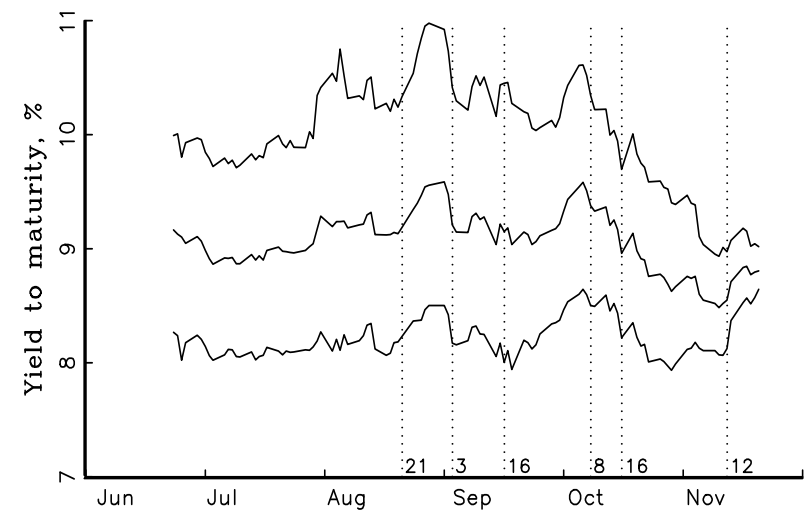

d. Euromark

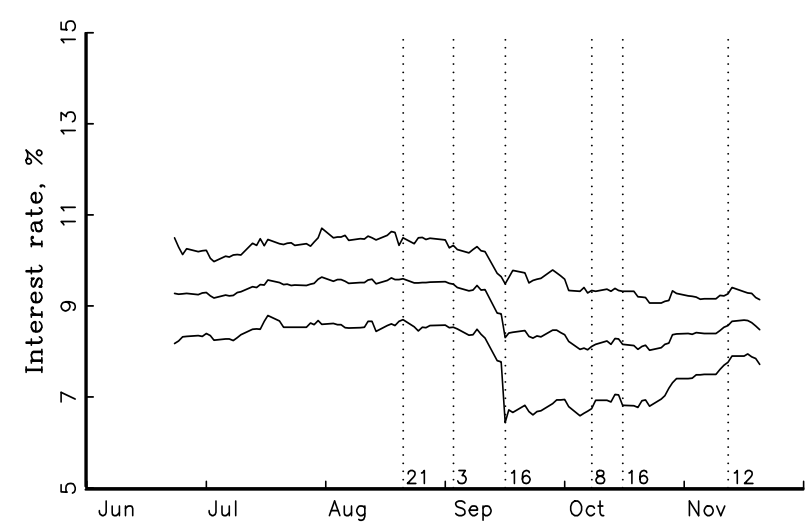

Figure 3: Expected values, 5th and 95th percentiles of estimated risk neutral distributions 
a. Option prices

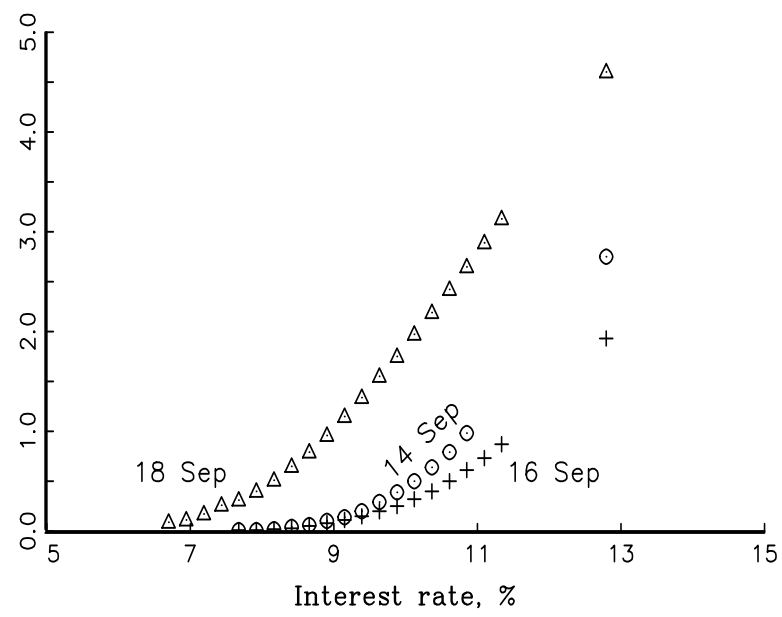

b. Probability density functions

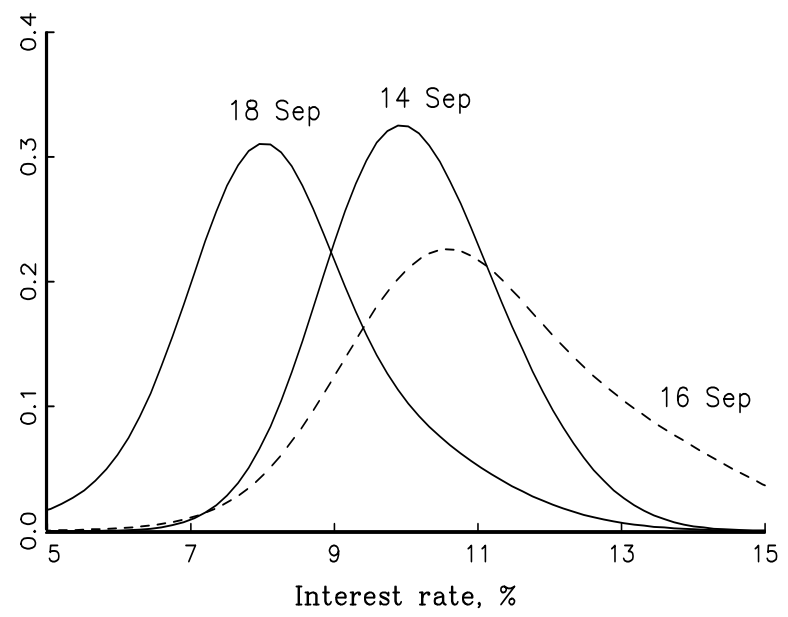

Figure 4: Data and results for short sterling interest rate

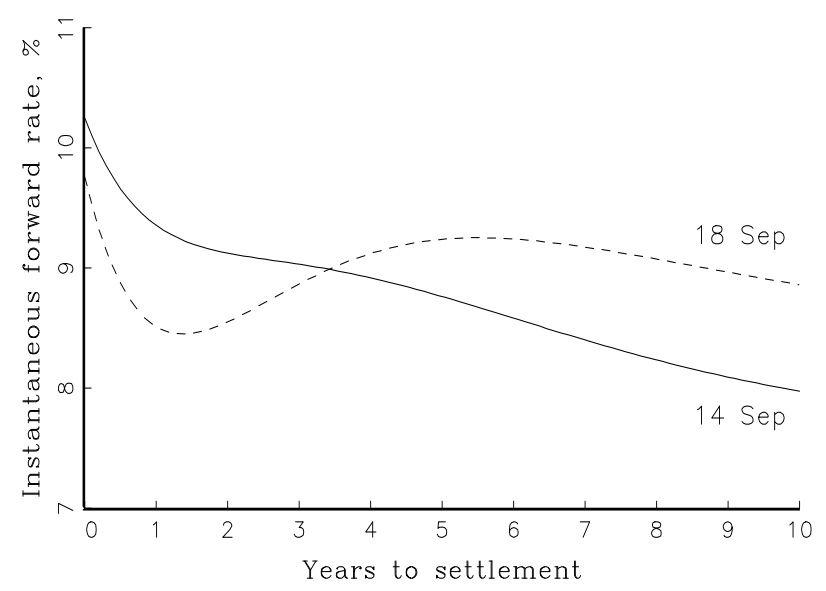

Figure 5: UK yield curve on 14 and 18 September 1992 
a. Estimates from different data sets

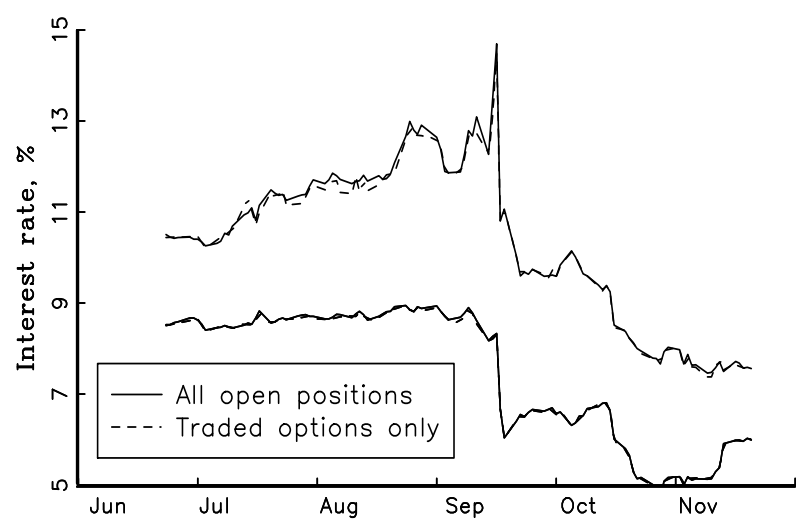

c. Risk neutral and 'true' percentiles

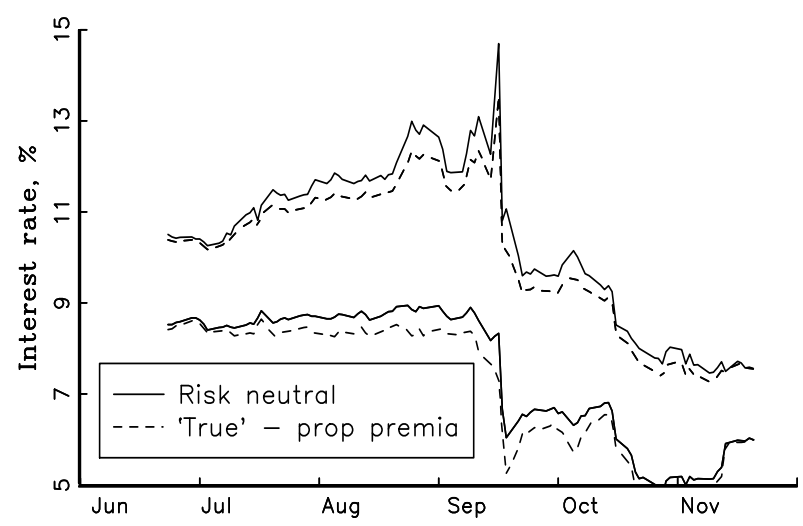

b. Risk neutral and 'true' percentiles

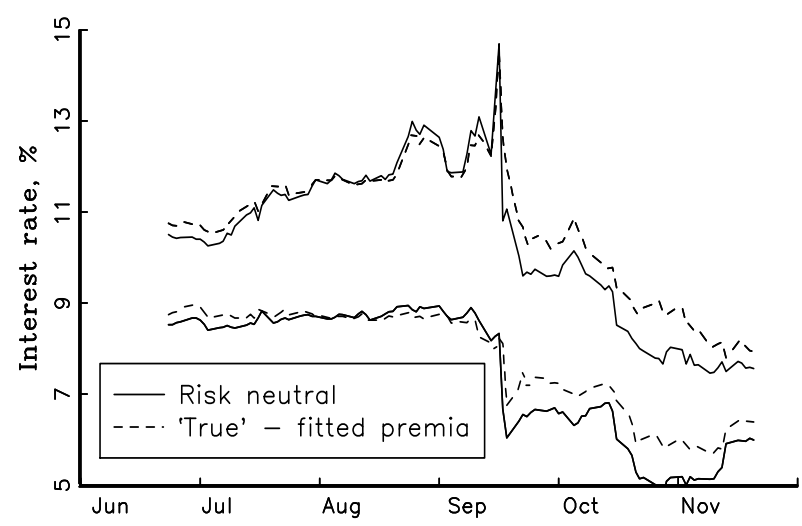

Figure 6: 5th and 95th percentiles of distribution of the short sterling interest rate 